\title{
sciforum
}

Conference Proceedings Paper

\section{Seasonal and annual daily precipitation risk maps for the Andean region of Peru}

\author{
Sergio Vicente-Serrano',*, Juan I. López-Moreno ${ }^{2}$, Kris Correa ${ }^{3}$, Grinia Avalos ${ }^{4}$, Cesar Azorin- \\ Molina $^{5}$, Fernando Domínguez-Castro ${ }^{6}$, Ahmed El Kenawy ${ }^{7}$, Miquel Tomas-Burguera ${ }^{8}$, Francisco \\ Navarro-Serrano ${ }^{9}$, Marina Peña-Gallardo ${ }^{10}$, Luis Gimeno"11, Raquel Nieto ${ }^{12}$
}

Published: 05/11/2017

Academic Editor: Tercio Ambrizzi

1 Instituto Pirenaico de Ecología, Spanish National Research Council (IPE-CSIC); svicen@ipe.csic.es

2 Instituto Pirenaico de Ecología, Spanish National Research Council (IPE-CSIC); nlopez@ipe.csic.es

3 Servicio Nacional de Meteorología e Hidrología (SENAMHI); kcorrea@senamhi.gob.pe

4 Servicio Nacional de Meteorología e Hidrología (SENAMHI); gavalos@senamhi.gob.pe

5 Department of Earth Sciences, University of Gothenburg; cesar.azorin-molina@gu.se

6 Instituto Pirenaico de Ecología, Spanish National Research Council (IPE-CSIC); f.dominguez@ipe.csic.es

7 Instituto Pirenaico de Ecología, Spanish National Research Council (IPE-CSIC); kenawy@ipe.csic.es

8 Estación Experimental de Aula Dei, Spanish National Research Council (EEAD-CSIC); mtomas@eead.csic.es

9 Instituto Pirenaico de Ecología, Spanish National Research Council (IPE-CSIC); fnavarro@ipe.csic.es

10 Instituto Pirenaico de Ecología, Spanish National Research Council (IPE-CSIC); marinapgallardo@ipe.csic.es

11 Environmental Physics Laboratory Universidade de Vigo; l.gimeno@uvigo.es

12 Environmental Physics Laboratory Universidade de Vigo; rnieto@uvigo.es

* Correspondence: svicen@ipe.csic.es; Tel.: +34-976-369-393

\begin{abstract}
We develop for the first time maps of annual and seasonal extreme precipitation risk in the Andean region of Peru. For this purpose, we used the complete daily precipitation records existing in Peru. In each meteorological station, we obtained series of events of de-clustered daily intensity, total precipitation duration, total magnitude and dry-spell length. Using a peak-overthreshold approach we fitted the annual and seasonal series of these variables to a GeneralizedPareto distribution, obtained the distribution parameters and validated the performance of different thresholds to obtain reliable estimations of the precipitation probability. The parameters obtained in the different meteorological stations were mapped using a universal krigging approach using the elevation and the distance to the ocean as co-variables. Maps of parameters were validated using a jack-knife approach and maximum expected precipitation intensity, magnitude, duration and dryspell length estimated for a period of 25 and 50 years. The reliability of the spatial methodology was validated comparing observed precipitation and estimated by the spatial modelling in the different stations.
\end{abstract}

Keywords: Extreme precipitation, Andes, Peru, Generalized Pareto 
The 1st International Electronic Conference on Hydrological Cycle (CHyCle-2017), 12 - 16 November 2017; Sciforum Electronic Conference Series, Vol. 1, 2017

\section{Introduction}

Extreme precipitation events cuase strong economic and social losses in the countries of South America [1]. Peru is frequently affected by extreme precipitation events, mainly associated to El NiñoSouthern Oscillation [2], being the mountainous areas of the Andes the most affected by these events [3]. Daily precipitation variables (e.g., daily intensity, the duration of the precipitation events, the total precipitation magnitude during the event and the dry spell length) may provide information on the hazard probability associated to rainfall [4]. Nevertheless, although high precipitation events and long dry-spells may cause strong impacts in the Andean region, there is not still a quantification of the probability of occurrence of high events that may help to develop robust maps on the probability of occurrence or the return period of high events [5]. Here we obtain for the first time probability maps of occurrence of precipitation events based on daily station data for the Andes of Peru.

\section{Data and methods}

We have used the complete daily precipitation data for the whole country of Peru. 233 daily precipitation series were available but after a careful quality control and reconstruction we worked with 178 series from 1973 to 2016 which cover the majority of the Peruvian Andes (Figure 1). From daily precipitation series we obtained the maximum daily precipitation for each precipitation event, the total duration of the event in days (consequtive days with precipitation), total precipitation magnitude during the duration of the event and the length of the dry spell periods (consecutive days with no precipitation).

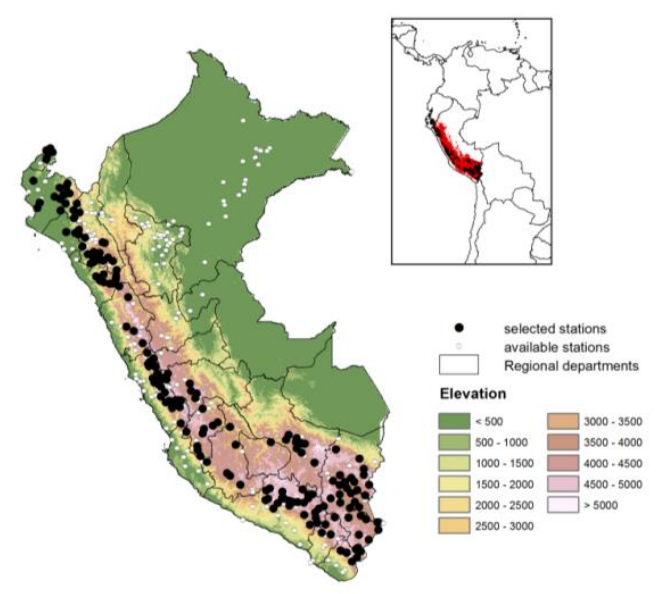

Figure 1. Study area and available meteorological stations

The methodology adopted in this study to sample the original data series for extracting the extreme observations was based on exceedance, or peaks over-threshold, sampling. After different analysis (not shown) we showed that the exceedance series of the four precipitation variables fit to a Generealised Pareto distribution and the most suitable threshold in relation to the available length of the sample and the probability estimations, was the $90^{\text {th }}$ centile of the series of the four variables. The Generalized Pareto parameters were estimated in each of the 178 meteorological stations at the seasonal and annual scales. These parameters were spatiallised at a spatial resolution of $5 \times 5 \mathrm{~km}$ by means of a universal kriging method [6], with the geographic latitude, longitude, and elevation of each grid cell being considered auxiliary variables. Spherical semivariograms with nugget effect were considered. The annual and seasonal parameter layers were validated using a jackknife resampling procedure and the observed and predicted data compared by means of the Mean Average Error and the Agreement index D. 
The 1st International Electronic Conference on Hydrological Cycle (CHyCle-2017), 12 - 16 November 2017;

Sciforum Electronic Conference Series, Vol. 1, 2017

Once we obtained the maps of annual and seasonal parameters, we calculated the probability that an event of magnitude $X$ (expressed in the original scale) will occur at least once in a period of $t$ years, according to:

$P(X \geq x \mid \propto, \kappa, t, \lambda)$

$$
=\left\{\begin{array}{c}
1-\left[1-\left(\kappa \frac{x-x_{0}}{\propto}\right)^{(1 / \kappa)}\right]^{\lambda t}, \kappa \neq 0 \\
1-\left[1-\exp \left(\left(-\frac{x-x_{0}}{\propto}\right)\right)\right]^{\lambda t}, \kappa=0
\end{array}\right.
$$

where alpha is the scale parapeter, kappa is the shape parameter, $\mathrm{x}_{0}$ is the origin of the distribution and lambda is a frequency parameter equaling the average number of occurrences of $X$ per year in the original sample.

\section{Results}

a)

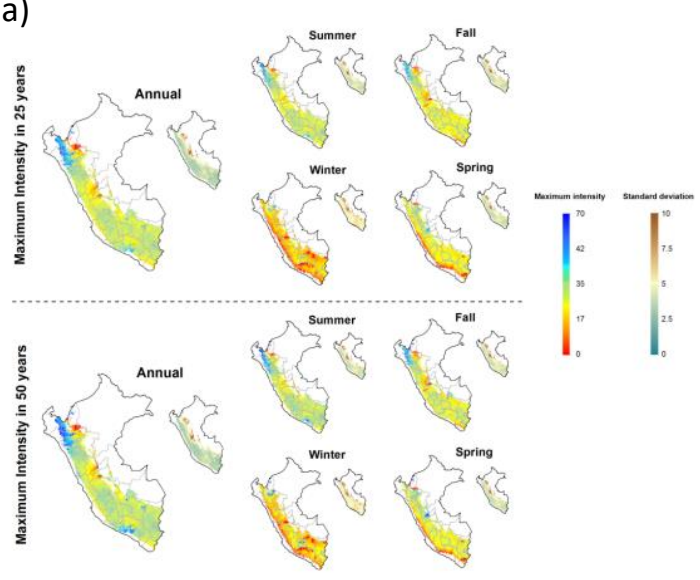

c)

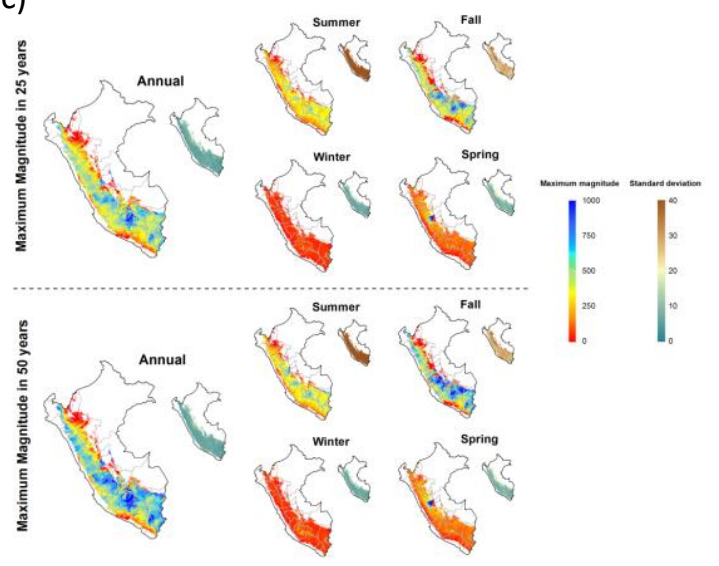

b)

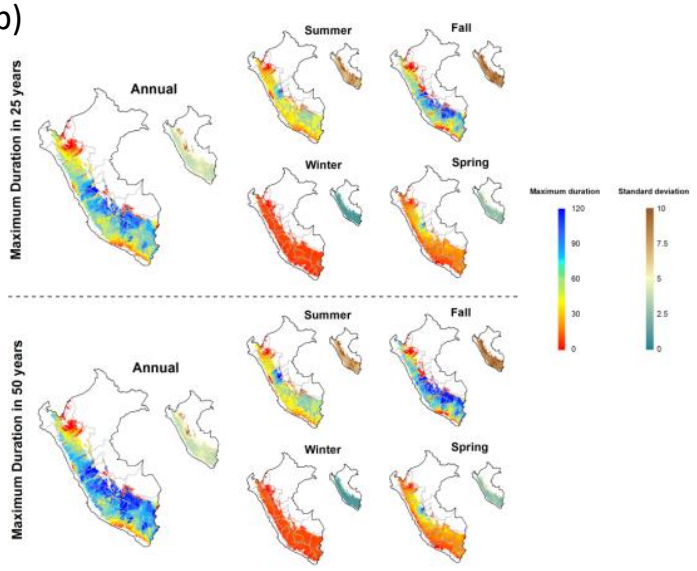

d)

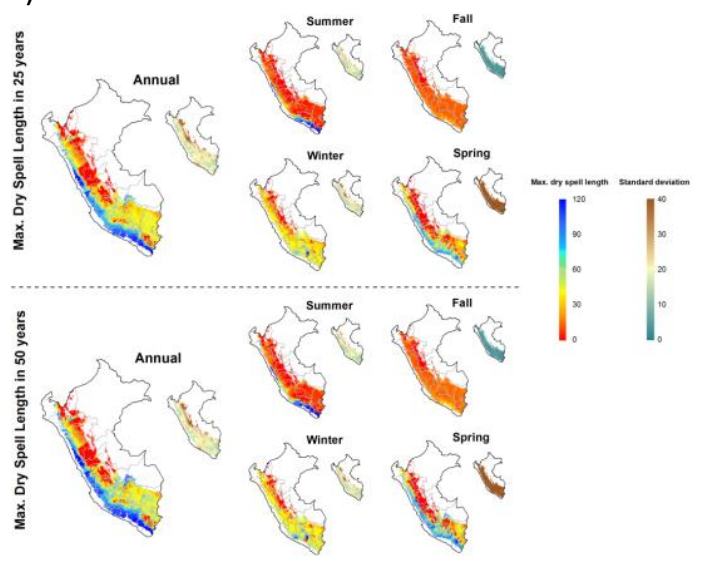

Figure 2. Spatial distribution of a) maximum annual and seasonal precipitation intensity, b) duration, c) magnitude and c) dry spell length in a period of 25 and 50 years. Small maps represent one standard deviation of the estimation.

Figure 2 shows the spatial distribution of the expected maximum precipitation intensity, duration, magnitude and dry spell length at the annual and seasonal scales for a period of 25 and 50 years. 
The 1st International Electronic Conference on Hydrological Cycle (CHyCle-2017), 12 - 16 November 2017; Sciforum Electronic Conference Series, Vol. 1, 2017

Maximum precipitation intensity shows noticeable spatial and seasonal differences. Higher precipitation intensity is expected in the Northwest area, in which the maximum expected in a period of 50 years is higher than $70 \mathrm{~mm}$. Maximum precipitation duration shows much more complex spatial patterns. It is expected a high maximum duration of the precipitation events, above 70 days of duration in a period of 50 years in large areas of the center and south of the Andes. The pattern resembles the behavior observed during the fall season, which also shows the highest standard deviation values. Maximum total precipitation magnitude during a rainfall event shows similar spatial patterns of precipitation duration, with the highest values recorded in the central-south Andes. The annual pattern is mostly related to the behavior observed in the fall season. Nevertheless, a higher variance is recorded for summer season, in which the spatial uncertainty of the estimations is the highest. Finally, the maximum expected dry-spell duration shows coherent spatial patterns, with maximum values (higher than 120 days with no precipitation in a period of 50 years) in the western slopes of the Andes of Peru.

In general there is stronger agreement between the on-site and predicted values by the krigging approach for precipitation intensity and dry spell length than for duration and magnitude. Nevertheless, there are important seasonal differences. For example, the mapping estimations for the precipitation duration for summer and spring or the precipitation magnitude for winter and spring show strong agreement with the on-site estimations based on the precipitation series (Figure 3 and Table 1).

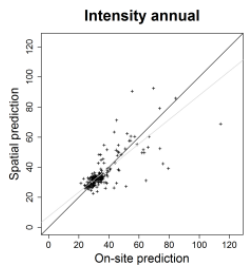

Duration annual

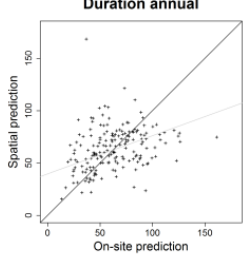

Magnitude annual

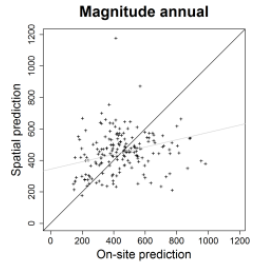

Dry spell length annual

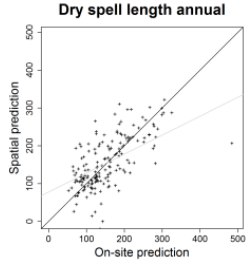

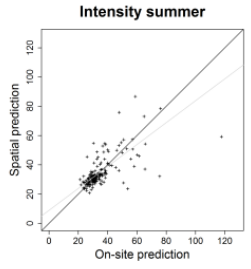

Duration summer
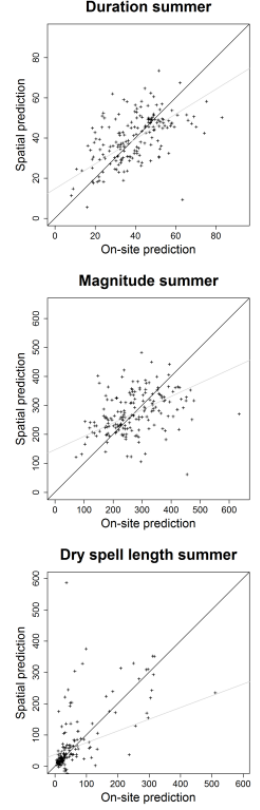

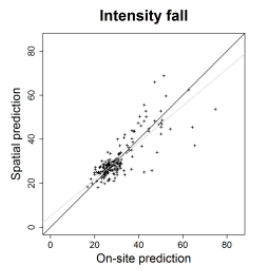

Duration fall

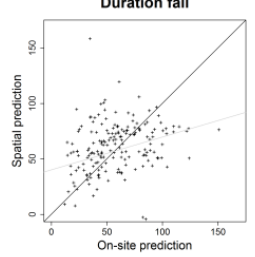

Magnitude fal

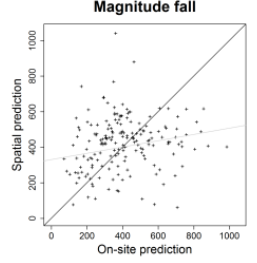

Dry spell length fall

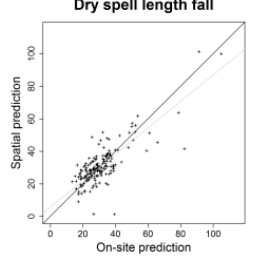

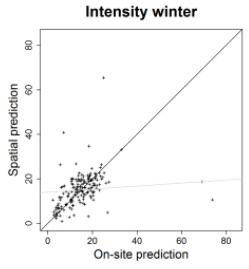

Duration winter

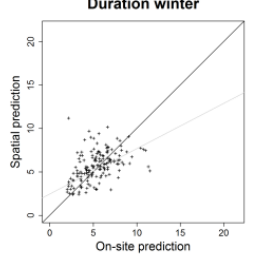

Magnitude winter

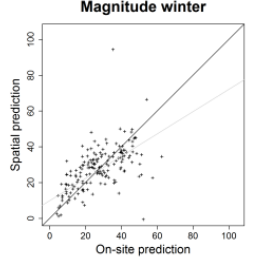

Dry spell length winter

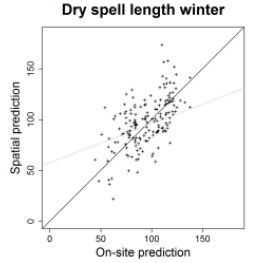

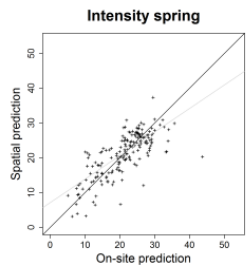

Duration spring

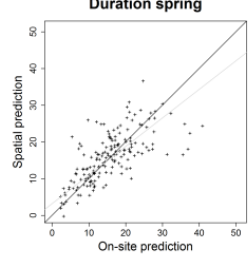

Magnitude spring

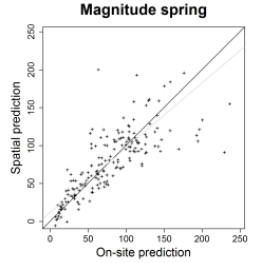

Dry spell length spring

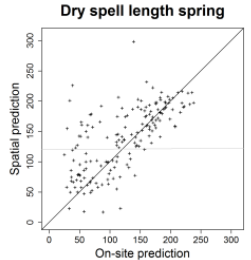

Figure 3. Relationship between the on-site estimation of the annual and seasonal maximum precipitation intensity, duration, magnitude and dry-spell length expected in a period of 25 years and the spatial prediction by means of the kriging universal models using the jack-nife approach. 
The 1st International Electronic Conference on Hydrological Cycle (CHyCle-2017), 12 - 16 November 2017; Sciforum Electronic Conference Series, Vol. 1, 2017

Table 1. Error/Accuracy statistics (D, MAE and weight $r$ ) between on-site estimation of the annual and seasonal maximum precipitation intensity, duration, magnitude and dry-spell length expected in a period of 50 years and the spatial prediction by means of the krigging universal models using the jack-nife approach.

\begin{tabular}{lllllll}
\hline & \multicolumn{3}{l}{ Maximum in 25 years } & \multicolumn{2}{l}{ Maximum in 50 years } \\
\hline & $\mathrm{D}$ & $\mathrm{MAE}$ & weight $\mathrm{r}$ & $\mathrm{D}$ & MAE & weight $\mathrm{r}$ \\
Intensity (annual) & 0.86 & 5.22 & 0.74 & 0.86 & 6.38 & 0.75 \\
Intensity (summer) & 0.80 & 5.11 & 0.65 & 0.81 & 6.68 & 0.67 \\
Intensity (fall) & 0.90 & 3.82 & 0.80 & 0.89 & 4.58 & 0.79 \\
Intensity (winter) & 0.31 & 6.05 & 0.03 & 0.13 & 9.80 & 0.03 \\
Intensity (spring) & 0.82 & 3.72 & 0.59 & 0.73 & 4.46 & 0.42 \\
Duration (annual) & 0.56 & 20.78 & 0.23 & 0.54 & 26.31 & 0.19 \\
Duration (summer) & 0.73 & 9.38 & 0.46 & 0.71 & 11.00 & 0.44 \\
Duration (fall) & 0.54 & 22.93 & 0.19 & 0.54 & 27.31 & 0.18 \\
Duration (winter) & 0.67 & 1.46 & 0.40 & 0.65 & 1.92 & 0.38 \\
Duration (spring) & 0.82 & 4.09 & 0.59 & 0.80 & 5.17 & 0.55 \\
Magnitude (annual) & 0.48 & 151.41 & 0.07 & 0.48 & 199.41 & 0.07 \\
Magnitude (summer) & 0.60 & 70.73 & 0.28 & 0.55 & 85.22 & 0.20 \\
Magnitude (fall) & 0.46 & 170.80 & 0.05 & 0.46 & 213.67 & 0.07 \\
Magnitude (winter) & 0.76 & 8.21 & 0.40 & 0.65 & 11.55 & 0.23 \\
Magnitude (spring) & 0.88 & 20.53 & 0.64 & 0.85 & 26.25 & 0.58 \\
Dry spell length (annual) & 0.75 & 44.13 & 0.61 & 0.69 & 52.51 & 0.52 \\
Dry spell length (summer) & 0.69 & 47.80 & 0.64 & 0.61 & 64.07 & 0.56 \\
Dry spell length (fall) & 0.88 & 5.64 & 0.85 & 0.88 & 7.29 & 0.83 \\
Dry spell length (winter) & 0.71 & 17.82 & 0.57 & 0.59 & 21.77 & 0.45 \\
Dry spell length (spring) & 0.03 & 113.19 & 0.13 & 0.02 & 247.45 & 0.09 \\
\hline
\end{tabular}

\section{Conclusions}

We have obtained for the first time maps of hazard of precipitation intensity, magnitude, duration and dry spell length for the Andean region of Peru based on peaks over threshold series and the Generalized Parteo distribution. Some of the maps show strong uncertainty given the random spatial distribution of the variables as a consequence of the complex topography and climate of the region. Nevertheless, the maps obtained provide a useful general assessment of the spatial distribution of the precipitation hazard probability over the region.

Acknowledgments: This work was supported by the research projects PCIN-2015-220 and CGL2014-52135-C0301 financed by the Spanish Commission of Science and Technology and FEDER, IMDROFLOOD financed by the Water Works 2014 co-funded call of the European Commission and INDECIS, financed by the ERA-NET Cofund for Climate Services of the European Research Area for Climate Services.. Marina Peña-Gallardo was granted by the Spanish Ministry of Economy and Competitiveness and Miquel Tomas-Burguera was supported by a doctoral grant by the Ministerio de Educación, Cultura y Deporte.

Author Contributions: All the authors contributed equally to the manuscript.

Conflicts of Interest: "The authors declare no conflict of interest." 
The 1st International Electronic Conference on Hydrological Cycle (CHyCle-2017), 12 - 16 November 2017;

Sciforum Electronic Conference Series, Vol. 1, 2017

\section{References}

1. Houston, J. The great Atacama flood of 2001 and its implications for Andean hydrology. Hydrological Processes. 2006, 20, 591-610.

2. Seiler, C., Hutjes, R.W.A., Kabat, P. Climate variability and trends in Bolivia. Journal of Applied Meteorology and Climatology, 2013, 52, 130-146.

3. Vilímek, V., Klimeš, J., Vlcko, J., Carreño, R. Catastrophic debris flows near Machu Picchu village (Aguas Calientes), Peru, Environmental Geology, 2006, 50, 1041-1052.

4. Begueria-Portugues, S., Vicente-Serrano, S.M. Mapping the hazard of extreme rainfall by peaks-overthreshold extreme value analysis and spatial regression techniques. Journal of Applied Meteorology and Climatology, 2006, 45, 108-124.

5. Beguería, S., Vicente-Serrano, S.M., López-Moreno, J.I., García-Ruiz, J.M. Annual and seasonal mapping of peak intensity, magnitude and duration of extreme precipitation events across a climatic gradient, Northeast Iberian Peninsula. International Journal of Climatology, 2009, 29: 1759-1779.

6. Pebesma, E.J. Multivariable geostatistics in S: The gstat package. Comput. Geosci. 2004, 30, 683-691.

(C) 2017 by the authors; licensee MDPI, Basel, Switzerland. This article is an open access article distributed under the terms and conditions of the Creative Commons by Attribution (CC-BY) license (http://creativecommons.org/licenses/by/4.0/). 